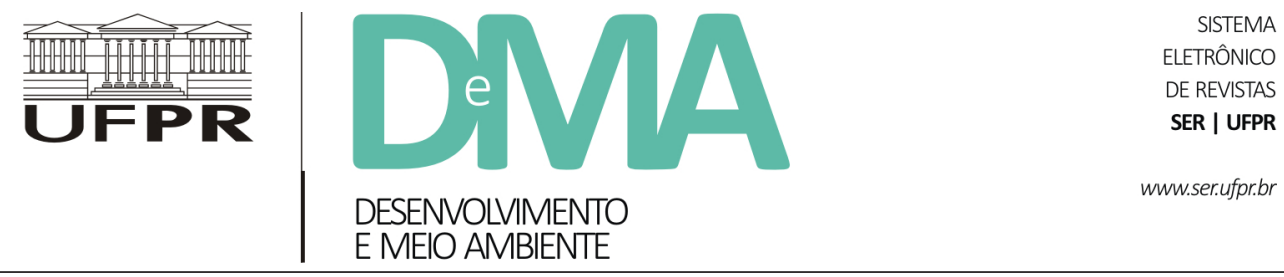

\title{
Circuitos (não tão) curtos de comercialização e a promoção de princípios agroecológicos: um estudo de caso na região da grande Florianópolis
}

\author{
Short (or not Too Short) Food Supply Chains and the Promotion of the \\ Agroecological Principles: A Study Case in the Greater Florianópolis/SC Region
}

\author{
Maurício da Trindade VIEGAS ${ }^{1 *}$, Oscar José ROVER ${ }^{1}$, Monique MEDEIROS ${ }^{1}$ \\ ${ }^{1}$ Universidade Federal de Santa Catarina (UFSC), Florianópolis, SC, Brasil. \\ *E-mail de contato: mauriciotviegas@hotmail.com
}

Artigo recebido em 19 de fevereiro de 2017, versão final aceita em 8 de novembro de 2017.

\begin{abstract}
RESUMO: O desenvolvimento acelerado dos mercados de produtos orgânicos tem provocado um processo denominado de convencionalização da agricultura orgânica. Este processo vem influenciando, diretamente, na manutenção dos princípios agroecológicos, bem como no acesso a esses mercados por agricultores socioeconomicamente vulneráveis. À luz de perspectivas teóricas, que embasam as temáticas da agroecologia e dos circuitos curtos de comercialização, o artigo reflete acerca da influência do avanço dos mercados orgânicos nos princípios agroecológicos da autonomia dos agricultores e da valorização da agrobiodiversidade nas unidades produtivas. As reflexões são resultado de um estudo de múltiplos casos, no qual foram realizadas entrevistas com responsáveis por diferentes canais de comercialização e agricultores da região da Grande Florianópolis/SC. As análises indicam que os processos de comercialização, quando organizados por coletivos de agricultores e - em certos casos - mesmo contando com o aumento no número de intermediários, reforçam os princípios agroecológicos.
\end{abstract}

Palavras-chave: comercialização de alimentos orgânicos; autonomia; agricultura familiar; Short Food Supply Chain (SFSC); redes agroalimentares alternativas.

ABSTRACT: The fast development of markets for organic products has led to a process called conventionalization of organic
agriculture. This process has been directly influencing the maintenance of agroecological principles, as well as
access to these markets by socioeconomically vulnerable farmers. In the light of theoretical perspectives based
on agroecology and short food supply chains, the paper reflects upon the influence of the organic markets on
the agroecological principles of the autonomy of the farmers and the valorization of agrobiodiversity in the
productive units. The analysis are the result of a multi - case study, in which interviews were conducted with 
managers from different marketing chains and farmers in the Greater Florianópolis/SC region. The analysis indicates that marketing processes, when organized by groups of farmers even with the increase in the number of intermediaries, in some cases, can reinforce agroecological principles.

Keywords: marketing of organic foods; autonomy; family farming; Short Food Supply Chain (SFSC); alternative food networks.

\section{Introdução}

Este artigo parte da problemática da convencionalização da agricultura orgânica, cuja implicação é relacionada à “[...] alteração das condições na participação do setor orgânico pelos agricultores, desencadeando a lógica da intensificação" (Guthman, 2004, p. 307, tradução nossa). A convencionalização vem mostrando que o desenvolvimento dos mercados orgânicos privilegia a inserção dos agricultores com maior potencial de organização e investimento econômico, excluindo os agricultores vulneráveis socioeconomicamente e fragilizando os princípios agroecológicos (Wilkinson, 2008).

Frente a essa problemática, no campo dos movimentos e das organizações que trabalham com agroecologia, tem se discutido quais estratégias comerciais poderão ser utilizadas de modo a viabilizar $\mathrm{o}$ acesso dos agricultores aos mercados, preservando os princípios agroecológicos e, ao mesmo tempo, abastecendo adequadamente os mercados. Para tal campo, é importante evitar as vias convencionais de comercialização, as quais estão marcadas por barreiras como burocracia e exigências de escala. Estudos apontam que os circuitos curtos de comercialização (CCC), entendidos como aqueles que promovem um maior contato entre o agricultor e o consumidor, proporcionam alternativas que favorecem os princípios agroecológicos (Guzmán et al., 2012; Kneafsey et al., 2013; Darolt et al., 2013).
Neste artigo, dentro do escopo da comercialização, buscou-se refletir acerca da forma de como diferentes circuitos comerciais influenciam nos princípios agroecológicos. Para isso, foram escolhidos os princípios da autonomia dos agricultores nos processos comerciais e da agrobiodiversidade, os quais foram analisados em diferentes canais de comercialização de itens orgânicos da região da Grande Florianópolis/SC. A região da Grande Florianópolis se caracteriza por uma grande concentração de moradores na área que une a capital do estado, Florianópolis, aos municípios de São José, Biguaçu e Palhoça. Vale mencionar que a região se refere a um importante espaço de consumo de alimentos orgânicos (Rover et al., 2015), merecendo atenção quanto às suas formas de abastecimento e às possíveis relações existentes entre estas e a preservação de princípios agroecológicos entre os agricultores envolvidos com a comercialização.

Com intuito de alcançar o objetivo proposto, o artigo está organizado em quatro seções além desta introdução. A primeira evidencia o processo de convencionalização da agricultura orgânica, suas influências na inserção dos agricultores nos mercados orgânicos e sua relação no que se refere aos princípios agroecológicos. A segunda, apresenta as bases teóricas dos CCC como elementos chave de comercialização agroecológica. A terceira, apresenta os métodos utilizados e os resultados alcançados por meio destes. Dentre os principais 
resultados, se destaca a correlação entre o aumento no número de intermediários, quando organizado por coletivos de agricultores, e o favorecimento dos princípios agroecológicos. Por fim, a última seção apresenta algumas considerações finais, evidenciando a necessidade de aprofundamento da teoria dos CCC dentro da perspectiva agroecológica e, também, considerando o cenário de desafios de comercialização.

\section{Os circuitos curtos de comercialização como superação da fragilização dos princípios agroecológicos}

A agroecologia emergiu tanto da busca dos consumidores por alimentos locais, limpos e de qualidade, quanto da necessidade de se pensar modelos sustentáveis de agricultura que garantam segurança alimentar, uso potencial do ambiente pelas futuras gerações e a inclusão social de agricultores em mercados alternativos (Renting et al., 2003; Guzmán et al., 2012). Isso se deu em contrapartida ao modelo convencional de agricultura, caracterizado pelo uso de monoculturas e de insumos de síntese química para maximização da produtividade.

A partir da abordagem agroecológica, tem sido cada vez mais importante pensar em estratégias sistêmicas que abordem a distribuição e a comercialização para ampliar e viabilizar as práticas propostas (Thrupp et al., 2014). Isso se reforça, dado o contexto de crescente aumento dos mercados para os produtos orgânicos e consequentes desafios que apontam para uma possível fragilização da aborda- gem agroecológica (Buck et al., 1997).

Um dos desafios trata-se da regulamentação da agricultura orgânica que incorpora a agricultura agroecológica, conforme a Lei brasileira $n^{\circ}$ $10.831 / 03^{1}$. Desta forma, um produto pode ser agroecológico, mas não obter o certificado orgânico, assim como pode ser certificado e sua forma de produção e comercialização desviarem dos princípios da agroecologia. Nesta perspectiva, a discussão internacional acerca da convencionalização da agricultura orgânica tem problematizado o risco de controle de mercado por poucas empresas que adquirem melhor colocação, devido à maior organização e escala, mas também às novas exigências que as empresas distribuidoras e varejistas passam a solicitar dos fornecedores. Esse conjunto de adversidades reduz o número de agricultores participantes nos mercados e induz a diminuição da diversidade produtiva, priorizando espécies de melhor retorno econômico (Guthman, 2004). Portanto, põe em risco a manutenção de dois princípios agroecológicos destacados neste artigo: a autonomia dos agricultores nos processos comerciais e a agrobiodiversidade de cultivos.

A autonomia nos processos comerciais deriva da ideia de autonomia produtiva de Ploeg (2008). Para o autor, uma unidade produtiva agropecuária deve ter uma base de recursos autocontrolada e autogerenciada, o que visa a melhoria e preservação dos recursos ambientais disponíveis, minimizando os riscos que afetem a "condição" de autodeterminação. Assim, a autonomia nos processos comerciais é compreendida como a capacidade dos agricultores participarem das decisões comerciais, permitindo

\footnotetext{
${ }^{1}$ De acordo com essa lei, o produto orgânico traz a garantia da isenção de agrotóxicos, adubos sintéticos e transgênicos, mediante a adoção de normas específicas, que garantem a certificação do agricultor.
} 
uma liberdade relativa para modificar seu caminho conforme seus interesses, com maior flexibilidade (Chauí, 2011). Como não há uma liberdade plena (Held, 1987), utilizou-se o termo "maior autonomia no mercado". Neste sentido, considerou-se que a maior participação dos agricultores na construção dos preços; as formas em que se realizam os acordos comerciais; o número de intermediários; e as exigências para comercialização, postas aos agricultores, constituem elementos importantes para analisar a sua maior ou menor autonomia nos processos comerciais.

A agrobiodiversidade é entendida como um elemento central para o equilíbrio agroecológico, correspondendo à biodiversidade de organismos no solo, às variedades de espécies vegetais agrícolas e não agrícolas, bem como à manutenção da vegetação espontânea e de animais silvestres (Gliessman \& Rosemeyer, 2010). Tudo isso favorece a criação de sinergismos nos agroecossistemas, os quais levam a uma maior estabilidade ambiental ${ }^{2}$ (Altieri, 2001). Salienta-se que esta pesquisa não pretendeu analisar a propriedade agrícola, pois a análise recai, sobretudo, na diversidade de cultivos comercializados pelos agricultores, já que seriam ao mesmo tempo a causa e o resultado de uma maior diversidade de produção.

Frente à emergente problemática da convencionalização, os atores sociais que atuam com uma abordagem agroecológica vêm buscando criar vínculos com os consumidores para inserir seus produtos através de novas formas e acordos para comercialização (Gliessman \& Rosemeyer, 2010).
A criação de vínculos entre consumidores e agricultores tem avançado devido às novas referências e padrões que se estabeleceram no mercado de alimentos. Tais padrões e referências podem estar vinculados com questões da alimentação e da saúde do consumidor (Guivant et al., 2010), mas também com modalidades de consumo consciente - como um ato político que prioriza algumas relações e produtos com formas de produção específicas (Portilho, 2009). Assim, a "qualidade" dos produtos vem ganhando relevância nas escolhas dos consumidores. Para Goodman (2003), nesse contexto, há um avanço em uma lógica na qual as convenções de qualidade são inseridas em dinâmicas de confiança, tradição e suporte, diferenciados conforme cada território. Antonelli (2011), por sua vez, indica que a participação dos atores nas dinâmicas concorrenciais do setor agroalimentar agrega, além dos preços, a capacidade de construir estratégias de diferenciação em termos de qualidade dos produtos e aproximação entre agricultores e consumidores.

Este artigo parte, portanto, do conceito dos Circuitos Curtos de Comercialização (CCC) como uma estratégia comercial para promover a agroecologia. O conceito de short food supply chains ou CCC, compõe uma das formas de redes agroalimentares alternativas (Alternative Food Networks - AFN). Estas redes têm sido cada vez mais estudadas, especialmente em países da Europa, como estratégias potenciais de desenvolvimento rural sustentável ${ }^{3}$ para agricultores a margem do mainstream convencional. Isto acontece pois envolvem produtos de qualidade diferenciada e, também, a

\footnotetext{
${ }^{2} \mathrm{O}$ conceito de agroecossistemas inclui um conjunto de questões as quais abarcam não somente a produção agrícola, mas também as interações biológicas, físicas, químicas, ecológicas e culturais, além dos possíveis impactos socioambientais de longo prazo.

${ }^{3}$ Utiliza-se o termo "sustentável", consolidado no Relatório Brundtland, no sentido de promover uma maior manutenção e uso do ambiente de forma longínqua, mas também no sentido de promover a maior segurança alimentar e inclusão social dos agricultores na produção e comercialização.
} 
possibilidade de driblar mercados competitivos e padronizados (Renting et al., 2003; Wilkinson, 2008). Os CCC fundamentam-se no acesso às informações sobre o produto pelos consumidores, permitindo novos julgamentos atrelados a possíveis características que possam vincular o alimento aos ambientes locais/regionais, bem como às práticas de produção ecológica (Renting et al., 2003; Marsden et al., 2000).

Nessa perspectiva, utiliza-se a ideia de aproximação entre agricultores e consumidores, possibilitando a troca de produtos diversificados, com a formação de relações diferentes das padronizadas, mais localmente definidas. Também, viabilizando novas possibilidades de combinação entre agricultura e natureza, que podem auxiliar a driblar os mercados convencionais (Marsden et al., 2000; Guzman et al., 2012). Autores brasileiros também têm adotado a teoria de CCC, em combinação com a perspectiva da agroecologia, como um caminho para viabilizar mercados alternativos (Darolt et al., 2013).

Para medir o quão curto é um circuito, alguns países consideram dois tipos de distâncias: a espacial e a relacional. A distância espacial remete à distância geográfica em "quilômetros", não havendo um referencial para o Brasil, mesmo que em alguns países haja definição de quilometragem máxima para um circuito comercial ser considerado curto ${ }^{4}$. Já para a distância relacional, há um consenso que considera - no máximo - um intermediário entre produção e consumo, podendo o circuito curto ser uma feira, uma cooperativa ou um restaurante, por exemplo (Chaffotte \& Chiffoleau, 2007; Galli \&
Brunori, 2013; Gúzman et al., 2012; Darolt et al., 2013). Tendo por base - neste artigo - a cidade de Florianópolis (Santa Catarina), definiu-se o recorte político-administrativo da região da Grande Florianópolis como distância espacial curta, na qual serão analisados os canais de comercialização quanto à importância dada ao fornecimento regional. Quanto ao número de intermediários, foram considerados curtos os circuitos contendo até um intermediário entre produção e consumo.

\section{Procedimentos metodológicos}

A região escolhida para o trabalho empírico apresenta potencial para produção agroecológica diversificada, isso devido a predominância de agricultores de pequena escala. Além de haver um potencial de consumo de alimentos orgânicos, devido encontrar-se em proximidade com grandes centros urbanos (Zoldan \& Mior, 2012). O estudo optou por trabalhar apenas com itens do tipo frutas, legumes e verduras (FLV), tendo em vista a maior presença de hortaliças na região da Grande Florianópolis e sua importância socioeconômica atrelada aos agricultores dessa região.

Como não há dados recentes que identifiquem os canais de comercialização na região, partiu-se de uma etapa exploratória, realizada em 2014, por meio da qual localizou-se os estabelecimentos que comercializam alimentos orgânicos no varejo em Florianópolis. No ano seguinte, partindo desses dados, foram realizadas entrevistas semiestruturadas $^{5}$ (Marconi \& Lakatos, 2009) com varejistas,

\footnotetext{
${ }^{4}$ Por exemplo, na França, um circuito curto é definido como aquele em que a distância máxima não ultrapassa $80 \mathrm{~km}$ do ponto de origem ao de consumo.
}

${ }^{5}$ A pesquisa foi aprovada pelo Comitê de Ética, cujo número do Certificado de Apresentação para Apreciação Ética (CAAE) é 45672215.2.0000.0121. 
intermediários e agricultores na região. Nos mesmos dias das entrevistas, foram realizadas - nos estabelecimentos de varejo - coletas de dados quantitativos nas gôndolas ali existentes. Ao total, foram feitas 14 entrevistas com varejistas: quatro supermercados, três mercados, três feiras, duas lojas e um sacolão, cuja classificação é ilustrada na Tabela 1. Além disso, foram elaboradas quatro entrevistas com intermediários e oito com agricultores. Assim, o estudo da comercialização de orgânicos da Grande Florianópolis foi composto por múltiplos casos, possibilitando a comparação de semelhanças e visualização de diferenças entre as variadas realidades (Yin, 2001). realizados com os varejistas e intermediários, até atingir a saturação de informações. Ou seja, o número de entrevistados foi determinado pela repetição de informações que indicaram que novas entrevistas não ofereceriam ganho qualitativo adicional significativo para a compreensão do fenômeno estudado.

De acordo com Gondim (2002), esse esgotamento de respostas sinaliza a possibilidade de identificar representações compartilhadas socialmente sobre determinado tema de interesse comum. Para analisar as entrevistas, de forma isolada e em conjunto, foi utilizado o método de análise de conteúdo (Rover, 2012), agrupando as informações das entrevistas em forma de quadro, por categorias de

TABELA 1 - Classificação dos estabelecimentos identificados na Ilha de Santa Catarina em 2014.

\begin{tabular}{cc}
\hline Estabelecimentos & Parâmetros \\
\hline Feira & $\begin{array}{r}\text { Predominância de itens in natura, ausência de caixa fixo e funcionamento não permanente. Uma } \\
\text { feira pode ser composta por uma ou mais barracas. }\end{array}$ \\
\hline Sacolão & $\begin{array}{c}\text { Semelhante às feiras, porém atuam em ambiente fechado. Também conhecidos como "fruteiras" } \\
\text { ou "verdureiras", caracterizados pela presença de ao menos um setor das vendas que apresente } \\
\text { preço único para diferentes produtos. }\end{array}$ \\
\hline Loja & $\begin{array}{r}\text { Normalmente, nesses estabelecimentos, há predominância de itens processados, produtos dife- } \\
\text { renciados e um ambiente decorado. As gôndolas não são dispostas paralelamente. }\end{array}$ \\
\hline Mercado & $\begin{array}{r}\text { Presença de gôndolas dispostas paralelamente. Possui entre um e três balcões de caixa. Asseme- } \\
\text { lha-se a um supermercado de porte reduzido. }\end{array}$ \\
\hline Supermercado & Presença de gôndolas dispostas paralelamente. Possui mais que três balcões de caixa. \\
\hline
\end{tabular}

FONTE: Adaptado de Rover et al. (2015, p. 15).

Os varejistas e intermediários entrevistados foram escolhidos de modo a permitir uma heterogeneidade de casos dentre aqueles com a maior diversidade de itens, buscando assim, o maior número de fornecedores. Os agricultores fornecedores foram escolhidos aleatoriamente, a partir dos contatos assuntos (Quivy \& Campenhoudt, 2005). Para melhor apresentação das análises, os agricultores foram organizados em grupos, de acordo com as semelhanças em seus perfis. 


\section{Resultados e discussões}

\subsection{Os canais de comercialização na Grande Florianópolis}

Em 2014, foi identificado um total de 45 lojas, 26 supermercados, 10 mercados, 6 feiras e 3 sacolões na Ilha de Santa Catarina, sendo que 38\% destes estabelecimentos comercializavam mais que 31 variedades de alimentos orgânicos, principalmente em supermercados e feiras (Rover et al., 2015). Foi revelado que a maior oferta e diversidade de itens orgânicos frescos é encontrada nas feiras, seguidas dos supermercados. Enquanto isso, os demais estabelecimentos (mercados e lojas) utilizam os orgânicos como parte da estratégia da "alimentação saudável" e os apresentam nas prateleiras mesclados aos itens conhecidos como "naturais", "integrais" e "sem glúten". Dessa forma, foi entendido que as lojas e os mercados não dão relevância significativa à comercialização dos itens orgânicos.

Dos 14 varejos entrevistados, com exceção do Sacolão A e da Feira C, foi possível notar que há uma demanda por fornecedores com volume de oferta expressivo, com regularidade e diversidade de itens - independentemente da localização de origem do produto. Esses critérios são mais bem entendidos quando a maioria dos varejistas relata a ausência de logística de fornecedores, os cuidados quanto à apresentação visual dos produtos, a regularidade de entrega, a padronização e a diversidade de itens.

Essas exigências compõem um cenário de qualificação necessária e de adequação obrigatória para acessar os varejos, dificultando assim, a inserção de agricultores individuais frente a concorrência com grandes varejistas (Wilkinson, 2008). Esse novo cenário requer organização para produção e logística, o que resulta na presença de intermediários nos canais de comercialização, sendo capazes de atender melhor a essas demandas (Buainain \& Batalha, 2007). A Figura 1, a seguir, ilustra os canais de comercialização identificados, ressaltando os casos nos quais a presença dos intermediários é destacada.

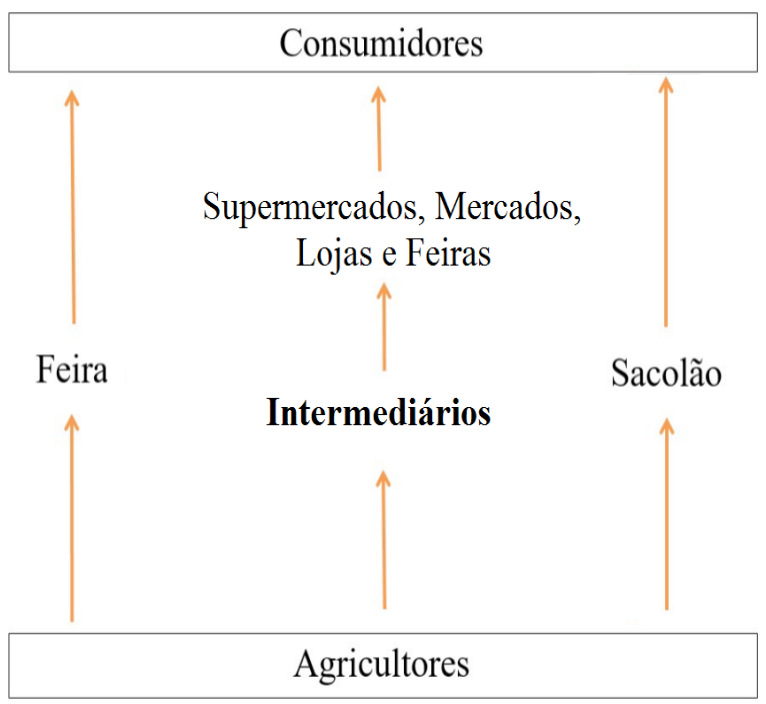

FIGURA 1 - Canais de comercialização de produtos orgânicos identificados na região da Grande Florianópolis. FONTE: Dados de campo.

Uma feira e um sacolão apresentam-se como exceções, pois estão voltados a um tipo de venda direta. O feirante responsável pela feira $\mathrm{C}$ possui foco em bolachas artesanais e utiliza a feira como um complemento de renda, reunindo itens diversificados - elaborados por três famílias próximas de sua residência. Essa experiência indica a presença 
de alguns laços de amizade, parentesco e vizinhança, os quais facilitam a parceria entre agricultores e minimizam intermediários. Assim, garantindo melhores preços para agricultores e consumidores, além da participação dos agricultores na decisão dos itens ofertados e a troca de informações entre o feirante e o consumidor, caracterizando um circuito curto (Renting et al., 2003).

O sacolão destacado também funciona como circuito curto, porém compõe uma organização familiar própria que higieniza e embala os itens, agregando valor e vendendo diariamente em um espaço de comercialização. O trabalho dessa família funciona de modo semelhante ao de uma grande empresa: envolve 10 trabalhadores fixos, permitindo uma maior diversidade e volume de produtos. $\mathrm{O}$ proprietário do Sacolão relatou evitar fornecedores devido a baixa qualidade dos produtos entregues por esses, o que lhe induziu a investir em sua própria unidade produtiva.

Os canais de comercialização, que atuam como intermediários, desenvolvem um papel estratégico como central atacadista, reunindo e distribuindo produtos para as lojas, supermercados, mercados e algumas feiras. Dos quatro intermediários entrevistados (A, B, C e D), B, C e D dão prioridade de venda para os supermercados. Conforme os relatos dos entrevistados, isso ocorre pois há um maior potencial de compra e venda por parte desses estabelecimentos, o que atrai o maior número de fornecedores/intermediários. Por outro lado, existem diversas exigências obrigatórias impostas para o fornecimento nos supermercados, como: a) rastreabilidade com código $\mathrm{QR}^{6}$; b) higienização e embalagem de itens, com as respectivas informações do produto e o código de barras do supermercado; c) colocação do produto na gôndola do supermercado, com o respectivo preço; e d) venda consignada, na qual o fornecedor arca com o prejuízo dos itens não vendidos.

A fim de que se supram essas exigências, os intermediários são obrigados a realizar o beneficiamento de itens com embalagem e higienização, agregando valor aos itens e aproveitando a venda com valor agregado para os demais estabelecimentos. Destaca-se a dificuldade, por parte de agricultores individuais, em fornecer para os supermercados, pois há uma restrição na diversidade de produtos exigida e uma dificuldade em atender as regras impostas pelos estabelecimentos de varejo.

Levando em conta a centralidade dos intermediários, é importante detalhar melhor o seu perfil e a relação com os agricultores fornecedores. Nesse sentido, a Tabela 2 apresenta a diversidade de FLV ofertada e a região de produção deste.

$\mathrm{O}$ intermediário $\mathrm{B}$, que é também produtor, possui menor diversidade de produtos comercializados quando comparado aos demais e vende a maior parte de seus produtos para um supermercado. Esse intermediário, recentemente, integrou-se à Rede Ecovida de Agroecologia ${ }^{7}$ para obter a certificação participativa $^{8}$, porém afirma - em entrevista - que

\footnotetext{
${ }^{6}$ Código de barras bidimensional que consta na embalagem dos produtos, o qual necessita de um smartphone, câmera e acesso à internet para ser escaneado. Esse código fornece a origem do intermediário que beneficiou o produto.
}

${ }^{7}$ A Rede Ecovida é uma rede de organização descentralizada composta por agricultores, técnicos, consumidores e outros interessados. Ela é orientada pela proposta de uma "agricultura alternativa" ao modelo hegemônico de produção, distribuição e consumo, priorizando as vendas diretas ou com o mínimo de intermediações de forma a manter os princípios agroecológicos (Rover, 2011).

${ }^{8}$ Essa modalidade de certificação tem menores custos e mobiliza os agricultores a se reunirem e se organizarem entre si sob os princípios da 
TABELA 2 - Perfil dos intermediários entrevistados quanto à diversidade de itens orgânicos ofertados e a sua distância de origem.

\begin{tabular}{ccccc}
\hline $\begin{array}{c}\text { Intermediários } \\
\text { entrevistados }\end{array}$ & $\begin{array}{c}\text { Número de varieda- } \\
\text { des FLV comercia- } \\
\text { lizada }\end{array}$ & $\begin{array}{c}\text { Número de variedades } \\
\text { da região da Grande } \\
\text { Florianópolis }\end{array}$ & $\begin{array}{c}\text { Número de variedades de fora } \\
\text { da região da Grande Florianó- } \\
\text { polis, mas de SC }\end{array}$ & $\begin{array}{c}\text { Número de va- } \\
\text { riedades de fora } \\
\text { de SC }\end{array}$ \\
\hline Intermediário A & 35 & 24 & 4 & 7 \\
Intermediário B & 1 & 1 & 0 & 5 \\
Intermediário C & 19 & 8 & 6 & 0 \\
Intermediário D & 28 & 24 & 4 & 5 \\
\hline
\end{tabular}

FONTE: Dados de campo

a diversificação é inviável economicamente, devido à complexidade produtiva, logística e a variação de preços entre os diversos produtos, e, por isso, adotou a especialização de um produto com maior rentabilidade. $\mathrm{O}$ intermediário $\mathrm{C}$ é, também, produtor convencional, que possui uma boa infraestrutura. Foi por meio de uma parceria com um supermercado que ele iniciou a produção e a distribuição de orgânicos, o que o levou a atender majoritariamente este mercado. O intermediário D compõe uma estrutura familiar que beneficia os produtos de agricultores próximos e vende - predominantemente - em supermercados e, complementarmente, em outros tipos de varejos?.

$\mathrm{O}$ intermediário $\mathrm{A}$, citado anteriormente como exceção, constitui-se de uma organização de agricultores pertencentes à Rede Ecovida de Agroecologia, que se difere dos demais intermediários. Nesse caso, existe um coletivo de agricultores que troca informações, realiza a certificação participativa e têm como perspectiva o desenvolvimento da agroecologia. Essa organização coletiva é estratégica para o acesso aos mercados pelos agricultores, já que promove a cooperação entre eles e, assim, o maior poder de barganha e a facilidade logística para a comercialização dos produtos (Buainain \& Batalha, 2007). Diferente dos demais, esse intermediário não realiza o processo de embalagem de itens, vende itens in natura para canais mais flexíveis como restaurantes e feiras, os quais se mostram menos exigentes em termos de padrões de qualidade e embalagens, favorecendo a autonomia dos agricultores que para ele fornecem (Chauí, 2011).

Para o intermediário A, a forma de comercialização é organizada conforme o interesse do próprio grupo de agricultores e não depende de um terceiro, o que valoriza e potencializa a autonomia e a agrobiodiversidade dos próprios agricultores. Além disso, como uma organização coletiva, ele é o único que não apresenta um histórico de redução no número de fornecedores. No que se refere aos casos relacionados aos Intermediários B, C e D, em suas entrevistas foi registrada uma redução no número de fornecedores de aproximadamente $50 \%$, $65 \%$ e $15 \%$ - respectivamente. Isso revela dificuldades de adequação desses agricultores, para o caso

confiança e transparência. Sua operacionalização é coordenada por uma entidade cadastrada, reduzindo a dependência da certificação por auditoria privada.

${ }^{9}$ Esse intermediário não forneceu com clareza as informações sobre seus fornecedores. 
desses entrepostos frente às mudanças do mercado, o que reforça a necessidade de se pensar caminhos alternativos às vias comuns de comercialização de alimentos, como destaca a teoria da convencionalização da agricultura orgânica (Buck et al., 1997).

Com base nas descrições acima, é possível compreender a atuação do intermediário A não tanto como um intermediário, mas como um ponto de atacado organizado pelos próprios agricultores, com maior fluxo de informação, o que aumenta a participação e possibilidade de diversificação. Tal constatação ratifica a importância de relativizar-se o acréscimo no número de intermediários, pois nem sempre irá compor uma perda no sentido de princípios agroecológicos e informações do produto.

Por outro lado, o intermediário A ainda é recente e não está isento de problemas de comercialização. Entre os principais problemas para viabilizar a comercialização estão: a logística, o grande número de fornecedores dispersos com pequenos volumes, a falta de organização produtiva dos agricultores e a diversidade de itens limitada à sazonalidade. Tais fatores vão de encontro aos princípios agroecológicos e dos circuitos curtos de comercialização, caracterizando desafios do processo de convencionalização da agricultura orgânica.

Nota-se que a organização do mercado induz à especialização produtiva, para facilidade organizacional e para o uso de circuitos longos - visando complementar a diversidade de itens e reforçando o risco da convencionalização (Guthman, 2004). A expressão desse processo de especialização destaca-se, no caso do intermediário B, o qual, ainda que pertencente a Rede Ecovida, não conseguiu viabilidade em mercados alternativos, voltando-se para o atendimento do supermercado com apenas um item.
Com relação a identificação dos agricultores fornecedores, essa mostrou-se de difícil realização entre todos os intermediários, pois o rótulo dos produtos não apresentava o endereço do agricultor, mas apenas do intermediário. A maioria dos varejos nem mesmo possuía contato com os agricultores fornecedores, restringindo o contato entre o varejo e intermediário. Isso obscurece a real origem dos itens orgânicos, aumentando o distanciamento relacional entre agricultores e consumidores, assim, dificultando a consolidação de relações mais curtas nesses varejos (Marsden et al., 2000).

Aprofundando a discussão com os relatos dos agricultores entrevistados, percebe-se - basicamente - três grupos diferenciados conforme a modalidade de certificação e o número de variedades comercializadas, como indica a Tabela 3.

Os agricultores 04 e 05 são oriundos do mesmo município do intermediário $\mathrm{B}$, e possuem certificação por auditoria, não compartilhando dos procedimentos participativos da certificação da Rede Ecovida, à qual pertence o intermediário B. Com relação aos preços, eles são definidos pelo intermediário, sendo que o Agricultor 04 considera o preço adquirido em seus produtos como bom, enquanto que o Agricultor 05 não o considera satisfatório. Essa contrariedade de interpretações pode estar relacionada ao fato do Agricultor 04 possuir maior potencial de investimento em tecnologia, o que facilita e amplia sua produção - diferente do outro que entende como insatisfatórios os preços. Isso indica que a escala pode alterar o acesso a melhores preços, o que pode pôr em conflito o ideal agroecológico frente às necessidades da comercialização, ratificando a teoria da convencionalização (Guthman, 2004). Por outro lado, os fornecedores do intermediário B possuem uma relação de venda 
mais livre, na qual há diálogo e negociação e não é exigida exclusividade de venda ao intermediário.

Por sua vez, os agricultores 06,07 e 08 não pagam os custos com a certificação, mas também não possuem o acesso ao certificado orgânico. Os agricultores são considerados parte da propriedade do respectivo intermediário (C ou D), assim, devem - obrigatoriamente - vender sua produção a ele, que também produz e detém o certificado, reunindo os produtos dos agricultores e certificando junto aos seus. Nesses casos, além da exclusividade de ven- da, constataram-se reclamações sobre os menores preços pagos aos agricultores (Tabela 4).

Além disso, houve a reclamação de plantar a variedade e a quantidade determinada pelos intermediários, que priorizam espécies com maior retorno econômico, o que reduz e prejudica a agrobiodiversidade, comprometendo o equilíbrio do agroecossistema (Gliessman \& Rosemeyer, 2010). Portanto, configura-se uma relação que minimiza as burocracias e os custos para os agricultores, porém, conforme salienta Chauí (2011), implica na redução

TABELA 3 - Caracterização dos agricultores quanto ao número de variedades comercializadas e destino de seus produtos.

\begin{tabular}{cccc}
\hline Entrevistados & $\begin{array}{c}\text { Modalidade de } \\
\text { Certificação }\end{array}$ & $\begin{array}{c}\text { Número de variedades } \\
\text { comercializadas }\end{array}$ & Canais de comercialização \\
\hline Agricultor 01* & Participativa & 13 & Intermediário A \\
Agricultor 02 & Restaurantes, feiras e pequenos varejos \\
Agricultor 03 & Auditoria & 17 & Mercados institucionais e feira \\
\hline Agricultor 04 & & 3 & Intermediários B e D \\
Agricultor 05 & Auditoria & 8 & Intermediário B \\
\hline Agricultor 06 & 10 & Intermediário C \\
Agricultor 07 & 8 & Intermediário C \\
Agricultor 08 & & Intermediário D \\
\hline
\end{tabular}

* Indica quais agricultores fazem feira por conta própria.

FONTE: Dados de campo.

TABELA 4 - Exercício analítico de comparação de preços recebidos pelos agricultores orgânicos ao longo dos canais de comercialização dos itens morango e alface lisa verde.

\begin{tabular}{ccccc}
\hline Item vendido & Para quem vende & $\begin{array}{c}\text { Quem define o } \\
\text { preço }\end{array}$ & $\begin{array}{c}\text { Preço recebido pelo } \\
\text { agricultor orgânico }\end{array}$ & $\begin{array}{c}\text { Preço pago ao agricultor } \\
\text { convencional }\end{array}$ \\
\hline Alface & Intermediário D & Intermediário & $\mathrm{R} \$ 0,57$ & $\mathrm{R} \$ 0,50$ \\
Alface & Intermediário C & Intermediário & Média $\mathrm{R} \$ 0,63$ & $\mathrm{R} \$ 0,50$ \\
Alface & Intermediário A & Intermediário & $\mathrm{R} \$ 0,90$ & $\mathrm{R} \$ 0,50$ \\
Alface & Feira C & Negociado & $\mathrm{R} \$ 0,70$ & $\mathrm{Não}$ identificado \\
Bandeja de morango & Intermediário B & Intermediário & $\mathrm{R} \$ 1,25$ & . \\
\hline
\end{tabular}

FONTE: Dados de campo coletados entre o final de agosto e início de novembro de 2015. 
da capacidade dos sujeitos em compreenderem e transformarem o seu percurso, reduzindo a autonomia, no momento em que sua própria condição de agricultor orgânico está condicionada pelo intermediário, mesmo em uma distância que poderia ser considerada espacialmente curta.

Os agricultores 01, 02 e 03 utilizam a certificação participativa promovida pela Rede Ecovida de Agroecologia. Esses agricultores procuraram por novos canais de comercialização - como feiras, mercados institucionais ${ }^{10}$ e pequenos varejos -, que favorecessem um maior controle na formação dos preços e maior liberdade na escolha das variedades produzidas. Nesse sentido, o agricultor 02 é um exemplo emblemático.

Anteriormente, o agricultor 2 comercializava seus produtos como convencionais em pequenos varejos, pois assim obtinha melhor renumeração do que com a venda aos intermediários. Recentemente, além de vender seus produtos como orgânicos adquirindo o diferencial de preços que o selo the garante, participa da organização de feiras e explora as melhores condições de comercialização. Essa iniciativa contribui para a construção de estratégias de diferenciação em termos de aproximação com os consumidores (Antonelli, 2011). Tal cenário evidencia uma maior autonomia desse agricultor no mercado e acaba por estimular outros agricultores a, também, seguirem esses passos.

Concernente aos preços recebidos pelos agricultores, percebe-se que canais mais diretos, como a Feira $\mathrm{C}$, possuem uma boa remuneração - favorecendo os princípios agroecológicos em circuitos curtos. Vale destacar que a presença do intermediário A nos processos de comercialização, embora aumente a distância relacional e espacial por buscar itens de locais distantes, resulta na melhor remuneração dos agricultores. Assim, assegurando melhores preços frente à tendência de redução de preços ocasionada pela lei econômica da oferta versus demanda (Arbage, 2006).

Além disso, o intermediário A possibilita a construção de uma maior autonomia aos agricultores, pois lhes dá flexibilidade de escolha para os volumes e variedades produzidas e comercializadas, o que favorece a valorização da agrobiodiversidade, dos tempos da natureza e das escolhas dos agricultores que lidam diretamente com os processos produtivos. Para além, a organização coletiva possibilita a participação na formação dos preços e na tomada de decisão sobre a comercialização, fortalecendo não apenas a autonomia de cada produtor, mas a autonomia coletiva dos participantes desta organização social. Portanto, esta forma não tão curta de circuito, aumenta as distâncias, porém otimiza a logística, garantindo melhor colocação no mercado e assegurando a manutenção de princípios agroecológicos pelos agricultores vinculados a ela.

\section{Considerações finais}

A maioria dos canais de comercialização estudados apresenta intermediários que facilitam as dinâmicas de comercialização. Entretanto, particularidades foram vistas para dois canais curtos

\footnotetext{
${ }^{10}$ Os mercados institucionais são canais de comercialização ligados aos Governos, Federal, Estaduais e Municipais. Por meio destes canais, compra-se os produtos da agricultura convencional ou orgânica de forma considerada direta. São exemplos desse tipo de mercado o Programa Nacional de Alimentação Escolar (PNAE) e o Programa de Aquisição de Alimentos (PAA).
} 
em uma das feiras e um sacolão. $\mathrm{O}$ feirante possui foco na venda de bolachas artesanais e aproveita as relações com os agricultores próximos para vender os produtos deles na sua feira, processo que acontece de forma dialogada, mantendo os princípios agroecológicos. Já o sacolão é caracterizado como uma empresa familiar que produz e comercializa, possuindo vários funcionários e evitando a inclusão e o envolvimento de agricultores fornecedores. À exceção destas particularidades, os demais estabelecimentos de venda no varejo não realizam vendas diretas. Eles complementam a diversidade e a regularidade de itens buscando produtos mais distantes e/ou utilizando maior número de intermediários, semelhante ao que ocorre nos varejos convencionais.

Em adição a isso, destacaram-se alguns estabelecimentos de varejo com maior potencial de domínio do mercado, os quais produzem inúmeras exigências, dificultando o acesso e participação de agricultores mais frágeis socioeconomicamente, ou seja, aqueles sem os recursos necessários para atender o grau de exigências posto pelos mercados. Isso leva uma parcela de agricultores a depender de intermediários, fator condicionante da sua inserção em tais canais de comercialização. Essa inserção nem sempre é favorável a esses agricultores, sendo que foi apresentado um histórico de redução de fornecedores nas centrais organizadas por terceiros, o que pode estar ligado com as dificuldades de adaptação dos agricultores e aos baixos preços pagos, o que leva à convencionalização da agricultura orgânica.

Por outro lado, foi visto que mesmo circuitos 'não tão curtos' de comercialização, quando mediados por uma adequada forma de reunião e distribuição de itens, por meio de mais um intermediário, podem valorizar os princípios agro- ecológicos. Isso pôde ser observado no caso em que o intermediário organizado coletivamente por agricultores da Rede Ecovida de Agroecologia, proporcionou maior liberdade e maior participação nas decisões de comercialização, gerando esforços para comercializar a diversidade de itens produzidos pelos agricultores. Por apresentar os melhores preços pagos aos agricultores em comparação aos demais estabelecimentos e a maior valorização da diversidade de cultivos, esse circuito 'não tão curto' mostrou ser um potencial mantenedor e reforçador dos princípios agroecológicos.

Nesse caso, essa organização acrescenta mais um intermediário e maior "quilometragem" aos produtos, porém é aqui compreendida como uma forma de adaptação agroecológica ao contexto convencional, pois a comercialização não é livre de problemas que confrontam constantemente o ideal agroecológico. A dificuldade logística é um exemplo desses problemas. $\mathrm{O}$ fato de existir um maior número de fornecedores com menores volumes dificulta a organização dos transportes. A falta de preparação de alguns agricultores para atender as demandas de um mercado competitivo e exigente pode ser compreendida como outro fator que merece atenção na fragilidade dessas relações. Ademais, defronta-se ainda com a maior complexidade organizacional de trabalho na agricultura quando há alta diversidade de itens na produção e comercialização.

Portanto, à luz dessas análises, sugere-se um aprofundamento maior da teoria dos $\mathrm{CCC}$, quando combinada com a perspectiva agroecológica, tendo em vista a presença de um ambiente competitivo e repleto de dificuldades para criação de vínculos mais próximos com o consumidor. Nesse sentido, estratégias como a intermediação por grupos de agricultores organizados podem destoar - parcial- 
mente - dos CCC ao acrescentar mais "quilometragem" e mais um intermediário. Porém, podem configurar-se como forma adaptativa ao mercado, garantindo a inserção e preservando os princípios da autonomia dos agricultores e da agrobiodiversidade.

Por fim, sugere-se que as análises avancem e aprofundem a relação e organização entre agricultores e consumidores para construção de mercados alternativos. Estudos sobre a organização de consumidores que buscam alimentos diferenciados, como vem ocorrendo na Europa (Kneafsey et al., 2013), poderão indicar um caminho para fortalecer as formas comerciais alternativas, mantendo os princípios agroecológicos.

\section{Referências}

Altieri, M. Agroecología: principios y estrategias para diseñar uma agricultura que conserva recursos naturales y asegura la soberania alimentaria. California, Berkeley: Universidad de California, 2001.

Antonelli, G. La prospettiva del valore nell'analisi delle filiere agroalimentari, Economia Agro-Alimentare, 13, 1-2, 2011.doi: 10.3280/ECAG2011-001002

Arbage, A. P. Fundamentos de Economia Rural. Chapecó: Argos, 2006.

Buainain, A. M.; Batalha, M.; O. (Coord.). Cadeia Produtiva de Produtos Orgânicos. V. 5. Brasília: MAPA/SPA/ IICA, 2007. Disponível em: http://www.ibraf.org.br/x_files/ Documentos/Cadeia_Produtiva_de_Produtos_Org\% $\% \bar{C} 3 \% \mathrm{~A}$ 2 nicos_S\%C3\%A9rie_Agroneg\% $\%$ C $3 \%$ B3cios_MAPA.pdf. Acesso em: fev. 2017.

Buck D.; Getz C.; Guthman J. From farm to table: The organic vegetable commodity chain of northern California. Sociologia Ruralis, 37, 3-20, 1997. doi: 10.1111/14679523.00033

Chaffotte, L.; Chiffoleau, Y. Vente directe et circuits courts: évaluation, définition et typologie. Les Cahiers de l'Ob- servatoire CROC, Montpellier, p. 8. 2007. Disponível em: http://pm22100.net/docs/pdf/04_CC_VD/130128_Cahier_ de_1_Obs1-INTERNET.pdf. Acesso em fev. $201 \overline{7}$.

Chauí, M. Cultura e democracia: o discurso competente e outras falas. São Paulo, SP: Cortez, 13. ed., 2011.

Darolt, M. R.; Lamine, C.; Brandemburg, A. A diversidade dos circuitos curtos de alimentos ecológicos: ensinamentos do caso brasileiro e francês. Agriculturas, 10(2), 2013.

Galli, F.; Brunori, G. Short Food Supply Chains as drivers of sustainable development. Evidence Document. Document developed in the framework of the FP7 project FOODLINKS (GA No. 265287). Laboratorio di studi rurali Sismondi, 2013. Disponível em: http://www.foodlinkscommunity. net/fileadmin/documents_organicresearch/foodlinks/CoPs/ evidence-document-sfsc-cop.pdf. Acesso em: fev. 2017.

Gliessman, S. R.; Rosemeyer, M. The conversion to sustainable agriculture: principles, processes, and practices. Nova York, Estados Unidos: Taylor \& Francis Group, 2010.

Gondim, S. M. Grupos focais como técnica de investigação qualitativa: Desafios metodológicos. Paidéia, Cadernos de Psicologia e Educação, 12(24), 149-161, 2002. Disponível em: http://www.scielo.br/scielo.php?script=sci_arttext\&pi$\mathrm{d}=\mathrm{S} 0103-863$ X2002000300004

Goodman, D. The quality 'turn' and alternative food practices: reflections and agenda. Journal of Rural Studies, 19, 1-7, 2003. doi: 10.1016/S0743-0167(02)00043-8

Guivant, J.; Spaargaren, G.; Rial, C. (Org.). Novas práticas alimentares no mercado global. Florianópolis: Ed. UFSC, 2010.

Guthman, J. The Trouble with 'Organic Lite' in California: a Rejoinder to the 'Conventionalisation' Debate. Sociologia Ruralis, 44(3), 301-316, 2004. doi: 10.1111/j. 1467-9523.2004.00277.x

Guzmán. E. S.; Montiel, M. S.; Hernández, D. G.; Sánchez, I. V.; Collado, A. C. Canales cortos de comercialización alimentaria en Andalucía. Espanha: Fundación Pública Andaluza, Centro de Estudios Andaluces, 2012. Disponível em: http://www.juntadeandalucia.es/export/drupaljda/CCC_alimentaria_en_Andalucia_2012.pdf. Acesso em fev. 2017.

Held, D. Modelos de Democracia. Tradução: Alexandre 
Sobreira Martins. Paidéia: Belo Horizonte, 1987.

Kneafsey, M.; Venn, L.; Schmultz, U.; Balázs, B.; Trenchard, L.; Eyden-Wood, T.; Bos, E.; Sutton, G.; Blackett, M. Jrc Scientific and Policy Reports: Short Food Supply Chains and Local Food Systems in the EU. A State of Play of their Socio-Economic Characteristics. Espanha: Joint Research Centre, 2013. Disponível em: http://ipts.jrc.ec.europa.eu/ publications/pub.cfm?id=6279. Acesso em fev. 2017.

Marconi, M. de, A.; Lakatos, E; M. Fundamentos de metodologia científica. São Paulo: Atlas, 6. ed., 2009.

Marsden, T.; Banks, J.; Bristow, G. Food Supply Chain Approaches: Exploring their Role in Rural Development. Sociologia Ruralis, 40(4), 2000.

Ploeg, J. V. D. Camponeses e Impérios Alimentares: lutas por autonomia e sustentabilidade na era da globalização. Trad. Rita Pereira. Porto Alegre: Editora da UFRGS, 2008.

Portilho, F. Novos atores no mercado: movimentos sociais econômicos e consumidores politizados. Política \& Sociedade, 8(15), 2009. doi: 10.5007/2175-7984.2009v8n15p199

Quivy, R.; Campenhoudt, L. V. Manual de Investigação em Ciências Sociais. Lisboa: Gradiva, 4. ed., 2005.

Renting, H.; Marsden, T. K.; Banks, J. Understanding Alternative Food Networks: Exploring the Role of Short Food Supply Chains in Rural Development. Environment and Planning A, 35, 393-411, 2003. doi:10.1068/a3510

Rover, O. J. Agroecologia, mercado e inovação social: o caso da Rede Ecovida de Agroecologia. Ciências Sociais Unisinos, 47(1), 56-63, 2011.

Rover, O. J. O método científico em ciências sociais: dos documentos, questionários e entrevistas à análise de enunciados. Florianópolis. REVISTA GRIFOS, 32-33, $13-$ 28, 2012. Disponível em: https://bell.unochapeco.edu.br/ revistas/index.php/grifos/article/view/2394
Rover, O. J.; Viegas, M. T.; Silva, B.; Gelbcke, D.; Morelli, N. Comercialização de alimentos orgânicos no varejo da ilha de Santa Catarina - Florianópolis/SC -. Relatório Final do Projeto de "Pesquisa sobre a comercialização em varejo de alimentos orgânicos na Ilha de Santa Catarina, Florianópolis/SC. Florianópolis: UFSC, 2015. Disponível em: <http://lacaf.paginas.ufsc.br/files/2015/12/relat\%C3\%B3rio-FINAL-pesquisa-varejo-org\%C3\%A2nico.-Fpolis.pdf $>$. Acesso em out. de 2017.

Thrupp, L. N.; Colozza, D.; Choptiany, J. The influence of food systems on the adoption of agroecological practices: Political-economic Factors that hinder or Facilitate change. In.: FAO - Food and Agriculture Organization of the United Nations. Agroecology for food Security And nutrition Proceedings of the FAO international symposium. Italy: FAO, 2014. Disponível em: http://www.fao.org/publications/card/ en/c/d1f541b5-39b8-4992-b764-7bdfffb5c63f/

Wilkinson, J. Mercados, redes e valores: o novo mundo da agricultura familiar. Porto Alegre: Editora da UFRGS: Programa de Pós-Graduação em Desenvolvimento Rural, 2008.

Yin, R. K. Estudo de caso: planejamento e métodos. Porto Alegre: Bookman, 2. ed., 2001.

Zoldan, P. C.; Mior, L. C. Produção orgânica na agricultura familiar de Santa Catarina em 2010. Florianópolis: Epagri, 2012. (Epagri. Documentos, 239). Disponível em: http://docweb.epagri.sc.gov.br/website_cepa/publicacoes/ agriculturaorganica.pdf. Acesso em fev. 2017. 